\title{
INOVASI PEMASARAN PORDUK GULA KACANG MELALUI SISTEM PENANDA LOKASI GLOBAL POSITIONING SYSTEM (GPS)
}

\section{Harminto Mulyo, Kartika Widiastuti, Zubaedah, Muhammad Verdy Fahrudin, Mochamad Handre Fidiyanto, \& Rahmawan Arniyanto}

Universitas Islam Nahdlatul Ulama Jepara, Indonesia minto@unisnu.ac.id 171330000082@unisnu.ac.id

Abstract: Increasing marketing innovation is very important in progress in entrepreneurship. Of course, in Micro, Small and Medium Enterprises (MSMEs). MSMEs is a commercial business whose management is carried out by individuals or individuals as well as business entities with a small scope, better known as micro. The problem faced by most small businesses or industries is that they do not have a Global Positioning System (GPS) partner business location marker system. Global Positioning System (GPS) is a navigation system that uses more than $24 \mathrm{MEO}$ (Medium Earth Orbit) satellites that can provide information on the user's position wherever they are. GPS also plays an important role in increasing marketing to MSMEs. By using GPS, it is easier for people to access the location of MSMEs. With community service related to MSMEs assistance in traditional types of peanut sugar, it is hoped that it can provide MSMEs solutions. The problem solving method used is based on a management approach in improving production and sales results with 3 (three) stages of program implementation, 
namely preparation, implementation and monitoring and evaluation.

Keyword: innovation, Marketing, GPS locator system

\section{Pendahuluan}

Kemajuan teknolgi mendorong mitra usaha kecil untuk melakukan praktek pemasaran dan bisnis yang baru. Internet adalah bagian dari kemajuan teknolgi, secara dramatis telah membentuk ulang pasar dan bisnis. Konsumen di seluruh dunia ter-exposed akan cara hidup dan konsumsi baru dan menginginkan banyak dari hal-hal yang mereka lihat. Bisnis pun mulai mengadopsi internet sehingga mendukung terciptanya Global Positioning System(GPS). Inovasi merupakan salah satu pilihan korporasi dalam menghadapi persaingan pasar dan pengelolaan yang berkelanjutan. Menurut Sutarno (2012), bahwa inovasi adalah transformasi pengetahuan kepada produk, proses dan jasa baru, tindakan menggunakan sesuatu yang baru. Dengan kata lain inovasi adalah modifikasi atau penemuan ide untuk perbaikan secara terus-menerus serta pengembangan untuk memenuhi kebutuhan pelanggan. Hal ini merupakan sebuah upaya dalam menghasilkan kesejahteraan bagi pelaku UMKM sebagai kompensasi dari hasil penjualan. Bahwa kompensasi inilah yang akan dipergunakan 
karyawan itu untuk memenuhi kebutuhan hidupnya.(Opan Arifudin , 2019)

Menurut Zaky Muhammad, dkk dalam penelitiannya tentang Perancangan Sistem Kendali Berbasis GPS pada kapal Tanpa Awak menyebutkan bahwa Global Positioning System(GPS) merupakan suatu sistem navigasi yang menggunakan lebih dari 24 satelit MEO (Medium Earth Orbit) yang dapat memberikan informasi posisi pengguna dimanapun berada. GPS juga berperan penting dalam meningkatkan pemasaran pada UMKM. Dengan menggunakan GPS, orang-orang lebih mudah untuk mengakses lokasi UMKM. (Zaky et al., 2018). Menurut Vernia Dellia Mila, dkk dalam penelitianya tentang Sosialisasi dan Pembekalan Strategi Pemasaran Produk olahan Pisang pada Siswa Pondok menyebutkan bahwa strategi pemasaran merupakan kegiatankegiatan yang dilakukan oleh pengusaha atau lainnya yang dilakukan untuk kelangsungan usaha yang bertujuan untuk meningkatkan pendapatan usaha atau laba. Dari penjelasan tersebut, hal - hal yang bertujuan untuk meningkatkan pendeapatan merupakan strategi pemasaran. Dengan demikian dengan dibuatkannya Sistem Penanda Lokasi Global Position System (GPS) dapat membantu pemasaran prduk dari UMKM.(Vernia et al., 2019) Pokok permasalahan yang dihadapi 
oleh UMKM Gula Kacang saat ini yaitu susahnya konsumen menemukan lokasi UMKM Gula Kacang, sehingga konsumen harus menanyakan lokasi terlebih dahulu untuk menemukan lokasi UMKM tersebut. Dari pada itu, konsumen juga sering mengalami salah arah dan tersesat ketika menuju lokasi UMKM. Dengan adanya permasalahan tersebut perlu adanya suatu inovasi dan solusi, Oleh karena itu, dari tim KKN UNISNU Kelompok 4 membuatkan sistem penanda lokasi Global Position System (GPS). Dengan diadakannya sistem penanda lokasi Global Position System (GPS), konsumen bisa lebih mudah menemukan lokasi UMKM tersebut, serta tidak perlu lagi menanyakan lokasi terbelih dahulu saat hendak menuju lokasi UMKM.

\section{Metode}

Metode dalam pelaksanaan pengabdian masyarakat dalam skema program Mahasiswa Kuliah Kerja Nyata (KKN) Tematik Covid-19 UNISNU Jepara mendampingi UMKM Gula Kacang Fita Dukuh Jetis Desa Bangsri Kecamatan Bangsri Kabupaten Jepara Jawa Tengah dilakukan dengan beberapa tahapan pelaksanaan program, yaitu sebagai berikut:

\section{Tahapan Awal}

Pada tahap awal ini dilakukan dengan observasi ke mitra Gula Kacang 
FITA dengan mengambil informasi-informasi penting dari pemilik usaha tersbut. Setelah mendapatkan data- data yang dibutuhkan terkait UMKM Gula Kacang FITA pengabdi menyiapkan program- program pengabdian masyarakat untuk di sosialisasikan dan menyiapkan peralatan, sarana- prasarana pendukung untuk pelaksanaan program secara bertahap berdasrakan prioritas program pendampingan UMKM Gula Kacang FITA Dukuh Jetis Desa Bangsri Kecamatan Bangsri Kabupaten Jepara Jawa Tengah.

\section{Tahapan Pelaksanaan}

Tahap pelaksaan pengabdi mengemukakan strategi proses pelaksanaan program pendampingan dengan membuatkan desain papan penanda usaha mitra Gula Kacang FITA. Desain tersebut di peruntukkan pada sistem penanda Banner, papan usaha 300M sebelum lokasi usaha mitra, dan situs web Global Position System (GPS) UMKM Gula Kacang FITA, diharapkan dapat memberikan dampak dan perubahan terhadap mitra.

\section{Tahapan Monitring dan Evaluasi}

Proses monitoring dan evaluasi terhadap pelaksanaan program dilkukan setiap 12 kali dalam 40 hari masa pengabdian masyarakat pendampingan UMKM Gula Kacang FITA Dukuh Jetis Desa Bangsri Kecamatan Bangsri Kabupaten Jepara Jawa Tengah.Metode evaluasinya 
yang digunakan menggunakan metode deskriptif kualitatif, yaitu penelitian yang ditujukan umtuk mendiskripsikan atau menggambarkan fenomena-fenomena yang ada, baik fenomena yang bersifat alamiah ataupun rekayasa manusia.

\section{Tahapan Pelaporan}

Pada tahapan ini, dilaporkan semua proses rangkaian kegiatan pengabdian dan output dari kegiatan ini.

\section{Hasil dan Pembahasan}

Berdasarkan hasil dari pengabdian masyarakat dengan program pendampingan UMKM Gula Kacang FITA Dukuh Jetis Kecamatan Bangsri Kabupaten Jepara Jawa Tengah dapat dijelaskan hasil dan luaran program serta dampaknya terhadap perubahan mitra selama proses pendampingan menghasilkan inovasi pemetaan sistem penanda lokasi melalui pemeberian aset yaitu papan nama industri mitra tersebut.

Dampak dari program pengabdian masyrakat dengan program pendampingan UMKM Gula Kacang FITA Dukuh Jetis Kecamatan Bangsri Kabupaten Jepara Jawa Tengah terhadap mitra sangat besar terkait mempermudah pencarian keberadaan lokasi Gula Kacang FITA. Program yang dilakukan adalah pendekatan inovasi pemasaran prduk 
gula kacang melalui sistem penanda lokasi berupa pemberian papan nama mitra. Hal yang dilihat dari berbagai tahapan pengabdian masyrakat yang dilakukan yakni sebagai berikut:

\section{Tahapan Persiapan}

Pada tahapan ini dilaksanakan observasi ke lokasi mitra dan wawancara dengan pemilik usaha. Dari hasil observasi dan wawancara dengan mitra ditemukan permasalahan yaitu belum memiliki papan nama di lokasi usaha mitra Gula Kacang FITA dan Mitra mengalami kendala dalam pembuatan penanda lokasi dalam bentuk Global Position System (GPS). Berdasarkan permasalahan yang ditemuai di atas maka solusi yang ditawarkan pengabdian kepada masyarakat pada UMKM Gula Kacang FITA sebagai mitra dalam kegiatan pengabdian ini pengabdi mendesain rancangan sistem penanda lokasi yang akan di pasang $300 \mathrm{M}$ sebelum tempat lokasi gula kacang. Desain papan memiliki ukuran 60 cm x $90 \mathrm{~cm}$ daan desain tiang papan memiliki ukran $200 \mathrm{~cm}$ diatas permukaan tanah dan $30 \mathrm{~cm}$ dikedalam tanah.

Gula Kacang FITA memang sudah familiar dikalangan masyarakat dengan cita rasa yang berkualitas. Solusi dari permasalahan pemasaran yang ditawarkan dalam program kemitraan masyarakat ini adalah memperluas pemasaran situs web Global Position System (GPS).

Vol. 3 No. 1, A pril 2021

Harminto Mulyo, Dkk| 45 Zurnal Pengabdian Masyarakat 


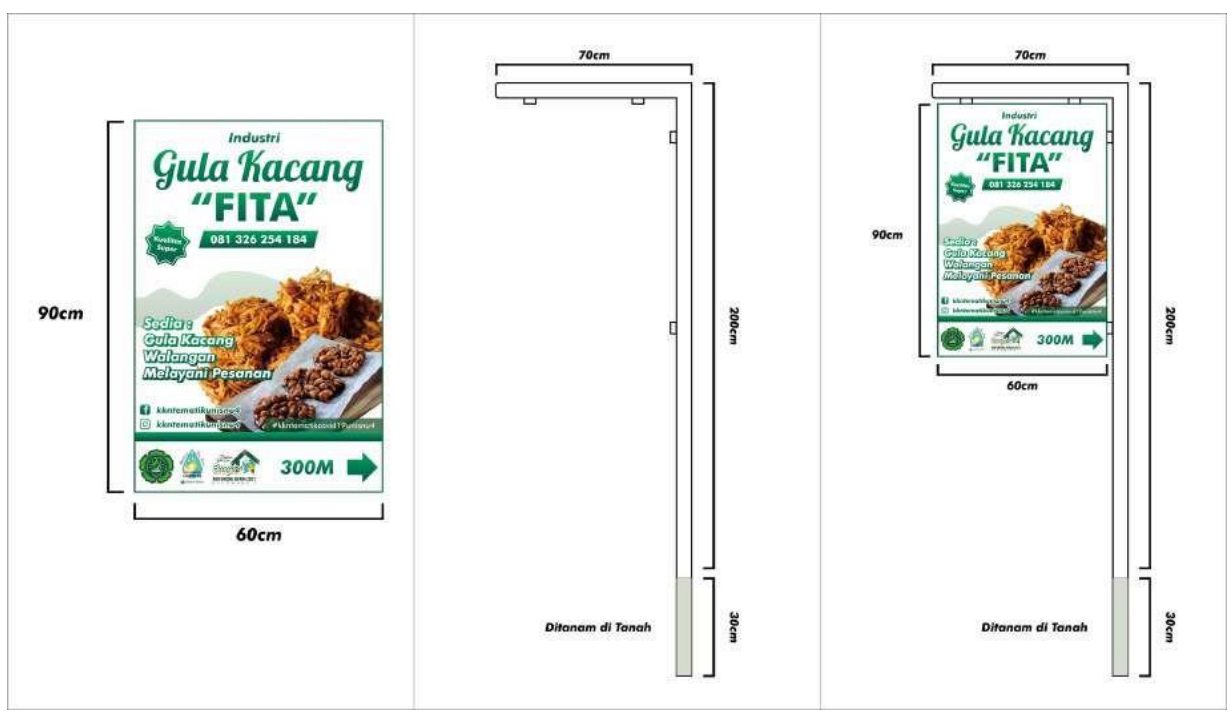

Gambar. 1. Rancangan pembuatan Papan Nama Usaha Gula Kacang FITA.

\section{Tahap Pelaksanaan}

Pemasaran merupakan serangkaian kegiatan yang dilakukan oleh produsen sebagai upaya menjual produk yang dihasilkan kepada konsumen. Mitra didampingi tim KKN Tematik Covid-19 UNISNU Jepara Kelompk 4 Desa Bangsri. Saat ini banyak konsumen yang belum mengetahui lokasi mitra Gula Kacang FITA. Kebanyakan konsumen melakukan transaksi jual beli secara tidak langsung. Konsumen melakukan pembelian melalui 
perorangan. Dengan adanya pembuatan situs web Global Position System (GPS) dan papan nama usaha mitra, agar konsumen dapat mengakses lokasi Gula Kacang FITA. Papan nama di desain terlebih dahulu oleh tim KKN UNISNU Jepara.

Solusi yang ditawarkan pada tahap persiapan dengan permasalahan-permasalahan usaha gula kacang akan dilaksanakan pada tahap pelaksanaan ini, kegiatan yang dilaksanakan pada tahap ini yiatu,

\section{Desain Papan Nama Usaha}

Tahap ini mitra usaha belum memiliki desain papan nama, baik dari sistem penanda lokasi di depan mitra usaha gula kacang, dan sistem penanda lokasi 300M dari jalan raya. Pengabdi melakukan 
pembuatan desain dengan arahan dan konsultasi dari pemilik usaha mitra gula kacang. Desain ini memberi makna pada warna yang khas dengan alam yaitu warna hijau dengan makna sumber kehidupan, kesegaran, dan warna aman.

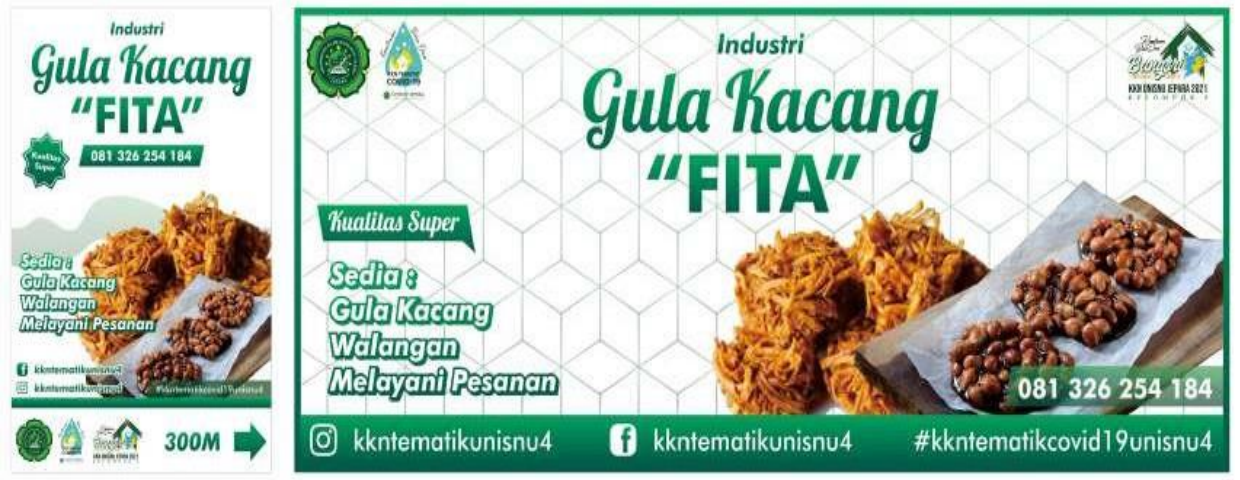

Gambar. 2. Desain Papan Nama dan Desain Banner Usaha Mitra Gula Kacang FITA.

\section{Pembuatajn Sistem Penanda Global Position System (GPS)}

Usaha mitra memerlukan sisitem penanda lokasi dengan menggunakan layanan pemetaan web Global Position System (GPS). Pengabdi mulai membuatkan GPS dengan mendaftarkan akun profil usaha, memasukkan koordinat lokasi gula kacang, mendaftarkan koordinat lokasi dalam layanan pemetaan web Global Position System (GPS), dan mengisi datanya sesuai mitra usaha Gula Kacang FITA.Dengan adanya program kerja penambahan lokasi Global 
Position System (GPS) akan memudahkan dalam pencarian lokasi Global Position System (GPS).

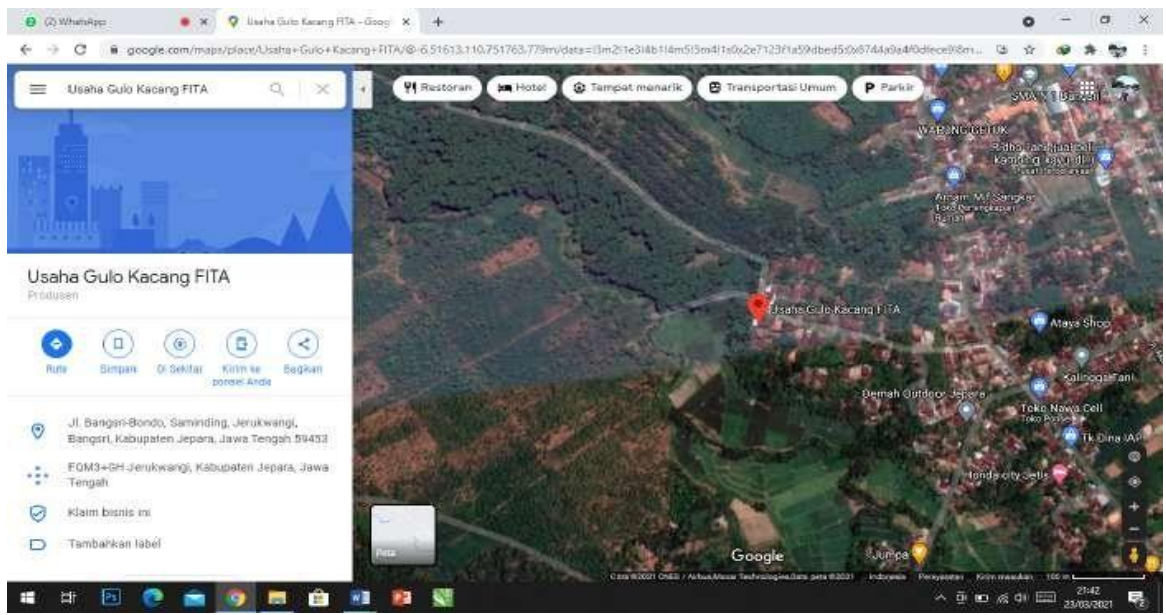

Gambar. 3. Pemetaan Usaha Mitra dengan Global Position System (GPS).

\section{Pemasangan Sistem Penanda Usaha}

Pengabdi beserta pemilik usaha gula kacang memasang papan penanda usaha mitra berupa banner di depan lokasi usaha tersebut, dan papan penanda usaha di pertigaan kurang dari 300M sebelum lokasi usaha mitra Gula Kacang FITA.Pemasangan papan penanda ini diharapkan dapat memudahkan calon konsumen untuk menemukan lokasi usaha gula kacang FITA. 


\begin{tabular}{|ll|l|}
\hline ISSN & $: 2656-5161$ \\
e-ISSN & $: 2686-0643$ & Ats-sidanah \\
\hline
\end{tabular}

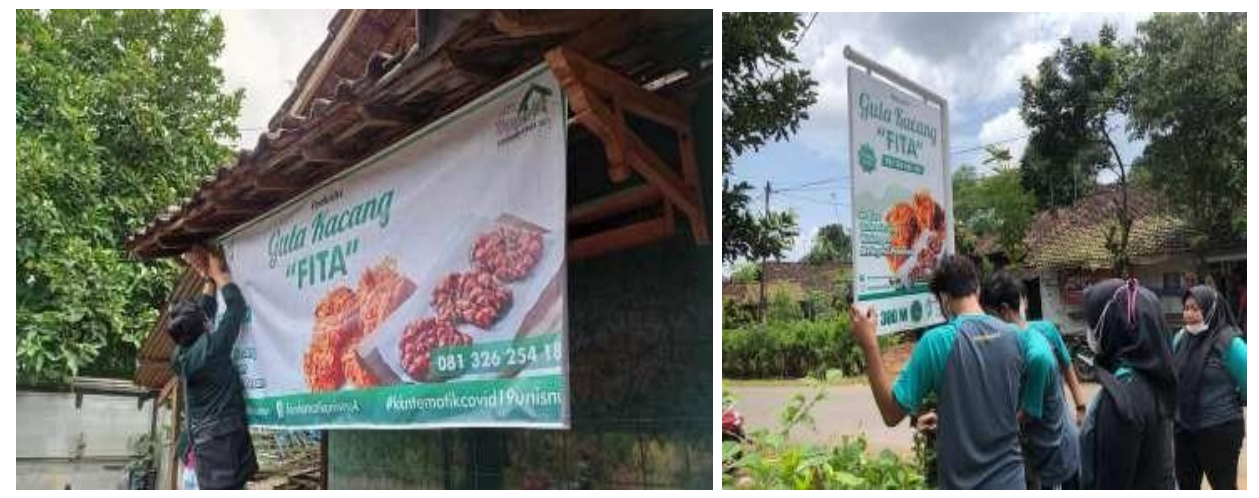

Gambar. 4. Pemasangan dan Pemberian Aset Papan Nama Usaha Mitra

Tahap Evaluasi

Pada tahap evaluasi proses kegiatan ini diukur keberhasilan program pengabdian masyarakat yang telah dilaksanakan terhadap usaha mitra. Evaluasi proses kegiatan pengabdian. Setiap tahapan kegiatan pengabdian telah dilaksanakan sesuai dengan rencana awal kegiatan. Output dari kegiatan juga telah sesuai dengan rencana. Berdasarkan wawancara yang dilakukan dengan mitra, kegiatan pengabdian ini juga telah memberikan manfaat yang besar bagi mitra. Hal ini terbukti dengan adanya pemberian sistem penanda lokasi yang berupa papan nama usaha maupun dengan pemetaan lokasi web Global Positioning system atau GPS usaha mitra Gula Kacang FITA dapat meningkatkan pemasaran dan memperluas usaha tersebut. Dapat dilihat pada gambar bahwa adanya pemetaan lokasi web Global Positioning system atau GPS

V o 1. $3 \mathrm{No} .1$, A p r i 122021
Harminto Mulyo, Dkk| 50 gurnal Pengabdian Masyarakat 
usaha mitra Gula Kacang FITA masyarakat sudah banyak mengakses bahkan menelusuri lokasi usaha Gula Kacang FITA dan juga memberikan repon positif pada pemilik usaha Gula Kacang FITA atas rasa dan kualitas produk.

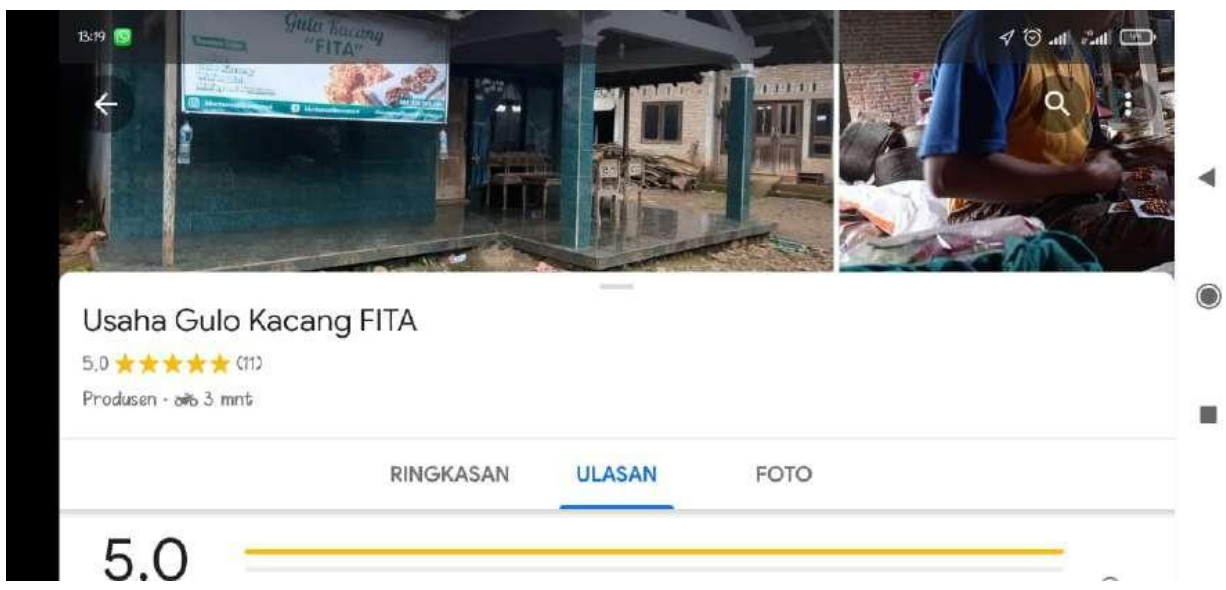

Gambar. 5. Hasil Respon Setelah Pemasangan Global Positioning system atau GPS

\section{Kesimpulan}

Program pengapdian yang telah dilakukan adalah untuk meningkatkan pemasaran melalui inovasi sistem penanda lokasi Global Positioning system atau GPS. Adapun metode yang digunakan adalah; 1) persiapan, 2) pelaksanaan serta 3) monitoring dan evaluasi. Hasil dari

Vol. 3 No. 1, A p ri 12021
Harminto Mulyo, Dkk| 51 Gurnal Pengabdian Masyarakat 
kegiatan ini adalah terciptanya inovasi sistem penanda lokasi gula kacang FITA meliputi banner penanda usaha mitra, papan nama, usaha mitra, dan penambahan layanan pemetaan web Global Position System (GPS). Respon pembeli terhadap adanya sistem penanda GPS maupun papan nama menjadi lebih mudah dalam mengakses tujuan menuju mitra tersebut untuk membeli produk gula kacang. Sisi positifnya adalah menjadikan calon konsumen yang sebelumnya belum mengetahui usaha mitra gula kacang menjadi tau dengan adanya mitra Gula Kacang FITA.

\section{Daftar Referensi}

Opan Arifudin, Fenny Damayanti Rusmana, Rahman Tanjung, \& Udin Wahrudin. (2020).

Inovasi Kemasan Dan Perluasan Pemasaran Dodol Nanas Di Subang Jawa Barat.

Dinamisia: Jurnal Pengabdian Kepada Masyarakat, 4(3), 408-417. https://doi.org/10.31849/dinamisia.v4i3.4469 8

Sutarno. (2012). Serba-Serbi Manajemen Bisnis. Journal of Chemical Information and Modeling, 53(9),

1689-1699.

Vernia, D. M., Widiyarto, S., Narsih, D., \& Mubasyira, M. (2019). 
Sosialisasi Dan Pembekalan Strategi Pemasaran Produk Olahan Pisang Pada Siswa Pondok. 3(2), 125-128.

Zaky, M., Mufti, A., \& Rahman, A. (2018). Perancangan Sistem Kendali Berbasis Gps (Global Positioning System) Pada Kapal Tanpa Awak. Jurnal Komputer, Informasi Teknologi, Dan Elektro, 3(2), 60-67. 


\section{JURNAL}

\section{As-Sidanah}

\section{Vol. 03 No. 1, April 2021}

